\title{
Technical Note: Optical properties of desert aerosol with non-spherical mineral particles: data incorporated to OPAC
}

\author{
P. Koepke ${ }^{1}$, J. Gasteiger ${ }^{1}$, and M. Hess ${ }^{2,3}$ \\ ${ }^{1}$ L-M-University Munich, Meteorological Institute, Theresienstr. 37, 80333 Munich, Germany \\ ${ }^{2}$ DLR - German Aerospace Center, Remote-Sensing Technology Institute, Oberpfaffenhofen, 82234 Weßling, Germany \\ ${ }^{3}$ RASCIN, Thalkirchner Str. 284, 81371 Munich, Germany \\ Correspondence to: P. Koepke (peter.koepke@lmu.de)
}

Received: 4 December 2014 - Published in Atmos. Chem. Phys. Discuss.: 12 February 2015

Revised: 30 April 2015 - Accepted: 30 April 2015 - Published: 29 May 2015

\begin{abstract}
Mineral particles, in general, are not spheres and so the assumption of spherical particles, instead of more realistic shapes, has significant effects on modeled optical properties and therefore on remote-sensing procedures for desert aerosol and the derived radiative forcing. Thus, in a new version of the database OPAC (Optical Properties of Aerosols and Clouds; Hess et al., 1998), the optical properties of the mineral particles are modeled describing the particles as spheroids with size dependent aspect ratio distributions, but with the size distributions and the spectral refractive indices not changed against the previous version of OPAC. The spheroid assumption is known to substantially improve the scattering functions but pays regard to the limited knowledge on particle shapes in an actual case. The relative deviations of the optical properties of non-spherical mineral particles from those of spherical particles are for the phase function in the solar spectral range up to $+60 \%$ at scattering angles of about $130^{\circ}$ and up to $-60 \%$ in the backscatter region, but less than $2 \%$ for the asymmetry parameter. The deviations are generally small in the thermal infrared and for optical properties that are independent of the scattering angle. The improved version of OPAC (4.0) is freely available at www.rascin.net.
\end{abstract}

\section{Introduction}

The optical properties of aerosol particles are the basis for modeling their direct radiative forcing (Lacis and Mishchenko, 1995; Haywood and Boucher, 2000; Yi et al., 2011) and correspondingly for their effect on climate (McCormick and Ludwig, 1967; Myhre et al., 2013). More- over, the optical properties are necessary for all inversion techniques used for aerosol remote sensing (Koepke and Quenzel, 1979; Kaufmann, 1993; Kalashnikova and Sokolik, 2002; Nousiainen, 2009). Thus, for an easy availability of spectral optical properties of aerosol particles, the software package OPAC (Optical Properties of Aerosols and Clouds) had been created (Hess et al., 1998).

The optical properties of aerosol particles in general are modeled using the size distribution and the spectral refractive indices of the particles. In the past, the assumption has commonly been made that the particles are spheres using Mie theory (Mie, 1908). This has different reasons: on the one hand, the assumption of spherical particles is reasonable in many cases, especially for water-soluble aerosol types under typical meteorological conditions with relative humidity higher than $50 \%$. On the other hand, the shape of individual particles is known only for a limited number of examples because it needs electron microscopy measurements. Thus, for actual conditions and for practical use, the shape of particles, particularly as function of size, is not available. But even if the particle shape were available, the problem remains that modeling of non-spherical particles would be complex and time consuming (Mishchenko et al., 2000; Kahnert, 2003). Thus, the use of Mie theory is often a good assumption (or the only possible assumption) and it has also been used in OPAC.

Desert aerosol, besides sea salt, forms the largest fraction of the atmospheric particles (d'Almeida et al., 1991; Kinne et al., 2006). Thus, desert aerosol is very important for the radiation budget and consequently for the climate, especially because it is distributed, often with high optical depth, over 
large areas. Since its amount shows very strong spatial and temporal variations (Sokolik et al., 2001), remote-sensing methods are important for desert aerosol research. However, remote-sensing is always based on the assumed particle characteristics.

Especially for mineral particles the optical properties modeled under the assumption of spherical shapes are questionable, since these particles are generated by mechanical processes which give rise to highly irregular particle shapes, as to be seen by electron micrographs (Falkovich et al., 2001; Kandler et al., 2011).

In comparison to spherical particles, the phase function of irregular particles generally shows increased sideward but reduced backward scattering if the particles are relatively large in comparison to the wavelength (Zerull et al., 1980; Koepke and Hess, 1988; Nousiainen, 2009; and see Fig. 1). Thus, if radiation data measured at short wavelengths are used to derive aerosol properties, the assumption of spheres may lead to wrong results. This holds also for particle properties derived from backscatter-lidar measurements (Gobbi et al., 2002; Wiegner et al., 2009; Sakai et al., 2014), since, amongst others, they are influenced by the lidar ratio, which combines backward scattering with the extinction coefficient. For passive remote-sensing from a satellite, an assumed wrong phase function of the particles can introduce significant retrieval errors and for consideration of the radiation budget of mineral particles in the solar spectral range, the assumption of spheres is a major source of error (Nousiainen, 2009). The amount of solar radiation scattered back to a radiometer at a satellite depends on the scattering angle, i.e. the angles of Sun and satellite, on the aerosol optical thickness, and on the reflectance at the ground. Thus the error in the case of assuming spherical particles is highly variable, and it is essential to use the appropriate scattering function (Horvath et al., 2006). The particle shape effect can cause up to $30 \%$ difference in dust forcing at the top of the atmosphere (Yi et al., 2011).

These aspects are the reason for accounting for the nonsphericity of mineral particles in OPAC (Hess et al., 1998) and therefore improving this algorithm. The user-friendly database and software package OPAC presents the singlescattering properties of 10 aerosol components that are given with size distribution and spectral refractive indices for a spectral range from ultraviolet to far-infrared. These components can be easily combined by the user to individual mixtures, i.e. to variable aerosol types, for which phase functions and other optical and microphysical parameters are modeled after user request.

If a particle is no longer assumed to be spherical, the possible variability of the particle shape is increased dramatically, and can range from spheres over spheroids and cubes to highly irregular particles (Cheng, 1980). Thus, if the shape of particles will be taken into account for general modeling of the optical parameters, it is necessary to decide for simplifications. Moreover, a model is necessary that allows one to consider reasonable shapes of non-spherical particles.
In this paper the non-spherical mineral particles are approximated as spheroids, since this substantially improves the agreement between modeled and measured optical properties (Mishchenko et al., 1997; Kahnert et al., 2005) and an appropriate theory exists, the T-matrix method (TMM) (Waterman, 1971).

In the new version of OPAC the optical properties of the mineral components are modeled as spheroids with the TMM code provided by Mishchenko and Travis (1998), with the aspect ratio distributions of the used spheroids varied with the particle size, as found by electron microscope investigations. The other microphysical properties of the components, the size distribution and the spectral refractive indices, have not been changed against the old OPAC. During the Saharan Mineral Dust Experiment field campaign (SAMUM1), which was located close to the Sahara and its mineral sources and used a lot of different aerosol measurement systems (Heintzenberg, 2009), desert aerosol size distributions have been measured both in situ on an airplane (Weinzierl et al., 2009) and inferred by the AERONET (Aerosol Robotic Network) inversion algorithm from ground-based photometer measurements. The results differ considerably (Müller et al., 2010), but the OPAC size distributions are in-between. Moreover, photometer measurements in the solar aureole (where the non-sphericity has no influence) and values modeled with OPAC type "desert" agree very well (Gasteiger, 2011). Also, optical properties of Saharan dust measured by aircraft in 1999 compare very favorably with OPAC results (Haywood et al., 2001) for radiative properties that are independent of the scattering angle, like asymmetry parameter, single scattering albedo, and specific extinction coefficient, for which the non-sphericity has negligible influence. Thus, the OPAC size distributions for desert aerosol are assumed to be adequate for a combination with the information on particle shape from SAMUM.

Also not changed against the old OPAC is the possibility of the flexible mixing of the components and of the outcome of OPAC, like optical properties depending on relative humidity and available for a large wavelength range. In the new version of OPAC (4.0), which is freely available for non-commercial use, the optical properties modeled for non-spherical mineral particles are taken into account directly for practical application.

\section{Methods}

\subsection{Non-spherical particle scattering}

The most suitable method to model the optical properties of mineral aerosol particles on a systematic basis (Wiegner et al., 2009) is TMM. It provides a solution of Maxwell's equations for the interaction of radiation with arbitrarily-shaped particles (Waterman, 1971) and is most efficient for rotationally symmetric particles. In our model the mineral particles 
are given as spheroids, originating from rotation of ellipses around one of their axes. Thus, an additional microphysical parameter that has to be taken into account is the aspect ratio $\varepsilon$, which is the ratio between the longest and the shortest axis (Dubovik et al., 2006). Moreover, the particles can be prolate (cigar-like) and oblate (disk-like) spheroids.

For the results in this paper and the new version of OPAC, the state-of-the-art TMM code from Mishchenko and Travis (1998) for randomly oriented particles has been used for the mineral components. The T-matrix calculations are supplemented by geometric optics calculations with the code of Yang et al. (2007) for large particles not covered by the TMM code. Wiegner et al. (2009) show the size coverage of the TMM code, which can model dust spheroids up to size parameters, $x=2 \pi r / \lambda$, around $110-120$ for aspect ratio 1.6 and smaller. For aspect ratio 3.0 the maximum size parameter of TMM is around 25. These codes have been used to create a data set of single particle scattering properties of spheroids covering a wide range of particle sizes, aspect ratios, and refractive indices. The grid of particle parameters in this data set is given in Gasteiger et al. (2011). The optical properties of the OPAC mineral components were calculated from this data set according to their microphysical properties described below. For the selection of the adequate aspect ratio distributions depending on particle size, measurements of the Saharan Mineral Dust Experiments (SAMUM I and SAMUM II) have been used (Kandler et al., 2009, 2011).

\subsection{Particle properties}

This paper presents an improvement of OPAC, by modifying the shape of mineral particles. The other microphysical parameters used in OPAC, such as, the particle size distribution and the spectral refractive indices, have been left unchanged.

In OPAC the aerosol particles are given as components (Shettle and Fenn, 1979; Deepak and Gerber, 1983) resulting from an internal mixture of particles of a certain origin. The particles of a component $i$ have a log-normal size distribution (Eq. 1).

$$
\begin{aligned}
& \frac{\mathrm{d} N_{i}(r)}{\mathrm{d} r}= \\
& \frac{N_{i}}{r \sqrt{2 \pi} \log \sigma_{i} \ln 10} \exp \left(-\frac{1}{2}\left(\frac{\log r-\log r_{\text {mod }, i}}{\log \sigma_{i}}\right)^{2}\right),
\end{aligned}
$$

where $N_{i}$ is the total number of particles of the component $i$ per cubic centimeter, $r$ the particle radius, $r_{\text {mod, } i}$ the mode radius of component $i$ with respect to the particle number, and $\sigma_{i}$ measures the width of the distribution. The radius $r$ of each spheroid is assumed to be the radius of a sphere with the orientation-averaged geometric cross section of the spheroid. The relative optical properties do not depend on $N$, thus they are given always for $N=1$. For absolute values of optical properties, e.g. for actual or individual conditions, $N_{i}$ must be chosen adequately for each component that will be taken into account.
Table 1. Microphysical properties of mineral components.

\begin{tabular}{lrrrrr}
\hline $\begin{array}{l}\text { Component } \\
\text { MIneral }\end{array}$ & $\begin{array}{r}r_{\text {mod }} \\
{[\mu \mathrm{m}]}\end{array}$ & $\sigma$ & $\begin{array}{r}r_{\min } \\
{[\mu \mathrm{m}]}\end{array}$ & $\begin{array}{r}r_{\max } \\
{[\mu \mathrm{m}]}\end{array}$ \\
\hline $\begin{array}{l}\text { Nucleation Mode } \\
\text { Accumulation Mode }\end{array}$ & MINM & 0.07 & 1.95 & 0.005 & 20 \\
Coarse Mode & 0.39 & 2.00 & 0.005 & 20 \\
& MICM & 1.90 & 2.15 & 0.005 & 60 \\
\hline
\end{tabular}

The mineral dust is described in OPAC with three components as given in Table 1: mineral nucleation mode (MINM), mineral accumulation mode (MIAM), and mineral coarse mode (MICM), with $r_{\text {mod }}$ and $\sigma$ the data of the size distributions, and $r_{\min }$ and $r_{\max }$ the borders that have been taken into account for modeling the optical properties.

These mineral components can be mixed externally, also together with other components, to form individual aerosol types. In general, both over deserts and for other aerosol conditions with a dominant mass of mineral particles, watersoluble particles (WASO) are also present. These particles can be assumed to be spherical. Their amount is usually small with respect to their mass per volume, but since the particles are small their numbers per volume may be large.

In OPAC the aerosol type "desert" is a mixture of more than $200 \mu \mathrm{g} \mathrm{m}^{-3}$ mineral particles and only $4 \mu \mathrm{g} \mathrm{m}^{-3}$ water soluble particles (WASO), resulting in 2000 particles per $\mathrm{cm}^{3}$ of WASO, and 300 per $\mathrm{cm}^{3}$ of mineral particles belonging to their three components. A small amount of WASO is generally taken into account in the following results, which show optical properties of mixtures of mineral particles.

The refractive indices of the components are wavelengthdependent (d'Almeida et al., 1991; Koepke et al., 1997). The particles of the mineral components all have the same refractive indices, since they are assumed to result from the same sources at the surface. The refractive index is given with an imaginary part that is responsible for the absorption properties of the particles.

To describe the shape properties of mineral particles of different size, for each of the three mineral components, the data of the "reference" case of SAMUM-1 have been used (Wiegner et al., 2009). The reference case was a situation with a very homogeneous desert aerosol layer up to $5 \mathrm{~km}$ above sea level which was very stable in time. The aspect ratio distribution of the particles was measured using electron microscopy and is given depending on particle size intervals by Kandler et al. (2009). For modeling the optical properties of mineral particles these wide aspect ratio distributions are applied to account for the large variety of the natural dust particle shapes. The belonging modeling results, compared to measured phase functions, are remarkably better than results when using only a single aspect ratio (Mishchenko et al., 1997; Nousiainen and Vermeulen, 2003). Moreover, all mineral particles are assumed to be prolate because this gives better agreement with measured scattering matrix elements 
Table 2. Aspect ratio distributions as function of particle radius interval discretized from measurement data of Kandler et al. (2009). The first line covers the measurement data from $\varepsilon=1.0$ to 1.3 , the last line covers $\varepsilon>2.9$ and the other values cover $\varepsilon$-intervals of 0.2 .

\begin{tabular}{cccc}
\hline$\varepsilon$ & $r<0.25 \mu \mathrm{m}$ & $0.25 \mu \mathrm{m}<r<0.5 \mu \mathrm{m}$ & $r>0.5 \mu \mathrm{m}$ \\
\hline 1.2 & 0.535 & 0.225 & 0.103 \\
1.4 & 0.289 & 0.212 & 0.234 \\
1.6 & 0.108 & 0.156 & 0.218 \\
1.8 & 0.040 & 0.110 & 0.157 \\
2.0 & 0.015 & 0.075 & 0.101 \\
2.2 & 0.007 & 0.054 & 0.065 \\
2.4 & 0.003 & 0.039 & 0.041 \\
2.6 & 0.001 & 0.028 & 0.027 \\
2.8 & 0.001 & 0.022 & 0.018 \\
3.0 & 0.001 & 0.079 & 0.036 \\
\hline
\end{tabular}

of dust particles than using oblate or mixtures of prolate and oblate spheroids (Nousiainen and Vermeulen, 2003).

It is worth mentioning that the aspect ratio distribution of mineral particles did not vary significantly during SAMUM1 and also not during the SAMUM-2 campaign, which was conducted further away from the dust source Sahara (Kandler et al., 2009, 2011). Thus, the selected aspect ratio distribution might be regarded as representative of Saharan dust.

The aspect ratio distributions depend on the size of the particles. For the reference case the relative frequency of particles with a given aspect ratio is available for 6 ranges of particle size (Kandler et al., 2009; Wiegner et al., 2009). Some of them have similar aspect ratio distributions so that only three radius ranges must be differentiated: for particles with $r<0.25 \mu \mathrm{m}$ the frequency decreases strongly with increasing aspect ratio. For particles with $r>0.5 \mu \mathrm{m}$ the shape distributions for all analyzed size intervals are similar, with a small maximum for the aspect ratio of about 1.5. Between these two regimes the particles between $r=0.25 \mu \mathrm{m}$ and $r=0.5 \mu \mathrm{m}$ have an aspect ratio distribution that gives a transition between the other two regimes (see Table 2).

Each OPAC mineral component contains particles in all radius ranges given in Table 2, with proportions that are varying according to the size distribution of the components (Table 1). To check the shape effects, as a first test (Kandler A) each mineral component is divided into the three radius ranges of Table 2 and the belonging aspect ratio distribution of each range is applied. This test is the most exact approach based on the available aspect ratio data. As a second test - with respect to the idea of OPAC to keep things easy - for all particles of each of the three OPAC mineral components a fixed aspect ratio distribution has been used: the distribution of $r<0.25 \mu \mathrm{m}$ for MINM, $0.25 \mu \mathrm{m}<r<0.5 \mu \mathrm{m}$ for MIAM, and $r>0.5 \mu \mathrm{m}$ for MICM (Kandler B). This test setup seems appropriate since the mode radii of the three components (Table 1) fall into these three radius intervals used to separate the aspect ratio distributions (Table 2). As a

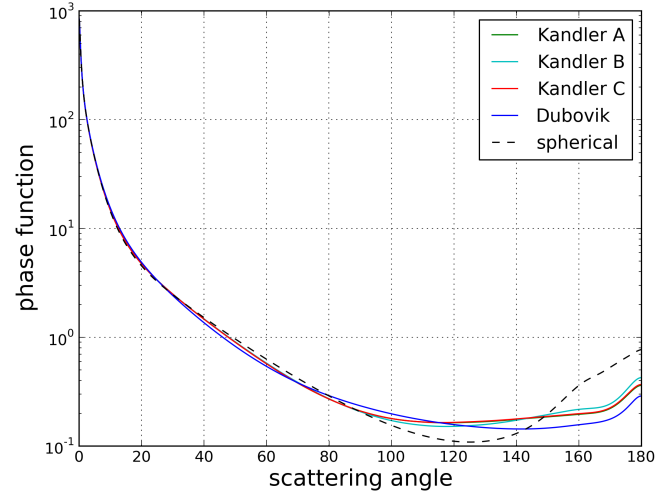

Figure 1. Phase functions at $0.55 \mu \mathrm{m}$ for the mixture of the mineral components after the aerosol type "desert", under the assumption of spherical mineral particles and for mineral particles with various aspect ratio distributions (see text for details).

third test (Kandler C), the second test is modified by assuming also for all particles of the accumulation mode (MIAM) the aspect ratio distribution that has been measured for particles with $r>0.5 \mu \mathrm{m}$. This use of the aspect ratio distribution measured for the larger particles also for MIAM was tested, since the maximum of the surface area distribution of MIAM is close to a radius of $1 \mu \mathrm{m}$. Finally a further association of radius and aspect ratio distribution has been tested: Dubovik et al. (2006) has derived aspect ratio distributions by analyzing measured phase functions, with the assumption that they are independent of the particle size. These are investigated as a forth test (Dubovik) for the particle shape effects.

As an example for the different considerations of the aspect ratio distributions, in Fig. 1 the phase functions are shown under the assumption of spherical particles and for non-spherical particles after the four tested radius dependent aspect ratio distributions. The phase functions are given for a wavelength $0.55 \mu \mathrm{m}$ (however the results at other wavelengths are similar, see Fig. 2), and as size distribution the combination of the three mineral components of the aerosol type "desert" after OPAC, including WASO at $0 \%$ relative humidity, has been used.

In Fig. 1 the increased sideward and reduced backward scattering is to be seen clearly which holds for all phase functions resulting from particles with non-spherical shape. The phase function after Dubovik is noticeably separated against those after Kandler A to C. But this result is not astonishing, since the direct electron microscopic investigations show that the aspect ratio distributions are size dependent, in contrast to the size-independent assumption by Dubovik. The phase functions after Kandler A (exact approach) and Kandler C are nearly identical, which means that the simpler assumptions in Kandler $\mathrm{C}$ give already correct results. Thus, for all optical property modeling of non-spherical mineral particles, both for the results shown in the following and for the new 
OPAC, the size dependent aspect ratio distribution after Kandler $\mathrm{C}$ is used.

\section{Results}

The effects of the particle shape are different for different optical properties which is shown in this paragraph for a variation of the optical properties available from OPAC. Examples are presented for the deviations between optical properties caused by mineral particles that are assumed as spheres and those assumed as spheroids with the aspect ratio distributions after Kandler C.

The phase function is very important for remote-sensing of desert aerosol and for its radiative forcing, and moreover, as mentioned above, for this optical quantity the effect due to non-sphericity is large, especially in the solar spectral range.

Thus, Fig. 2a shows the phase function for the two particle shape assumptions, for the mixture "desert" (Hess et al., 1998) and for different wavelengths. The assumed shape variation (spherical or non-spherical) is modeled only for the mineral particles: MINM $269.5 \mathrm{~cm}^{-3}$; MIAM $30.5 \mathrm{~cm}^{-3}$, MICM $0.142 \mathrm{~cm}^{-3}$. The $2000 \mathrm{~cm}^{-3}$ WASO are always assumed as spherical.

The phase functions show the known strong forward peak of aerosol particles, which is not influenced by the particle shape. It is increasing with increasing size parameter, and thus decreasing with wavelength. The particle shape effect is to be seen clearly in Fig. 2a in the backward scattering region, but more pronounced in Fig. $2 \mathrm{~b}$, where the belonging percentage deviations between the phase functions for particles with size dependent aspect ratio distributions and for spherical particles are shown.

The effect of the particle shape is up to almost $+60 \%$ at scattering angles around $130^{\circ}$ and $-60 \%$ around $170^{\circ}$ in the backscatter region. The effect decreases with increasing wavelength and is nearly negligible at $10 \mu \mathrm{m}$, as also shown. The reason is that the shape properties of the particles become less relevant if the wavelength of the radiation becomes larger relative to the particle size. In contrary, the effect of the particle shape is relatively low at $350 \mathrm{~nm}$, but this results from the strong absorption of the mineral particles at this wavelength, which reduces the scattering effects in general and thus is dominant in comparison to the shape effect. The effect of the particle shape is strongest in the solar wavelength range, which is often used for aerosol remote-sensing and which is essential for radiative forcing and thus for climate effects. This documents again the need to take the nonspherical shape of mineral particles into account for remotesensing or climate studies.

As mentioned, the aspect ratio distribution depends on the particle size. Thus, size distributions with different amounts of small and large particles may result in different variations of the phase function compared to that under the assumption of spheres. Since the life time of big particles in the atmo-
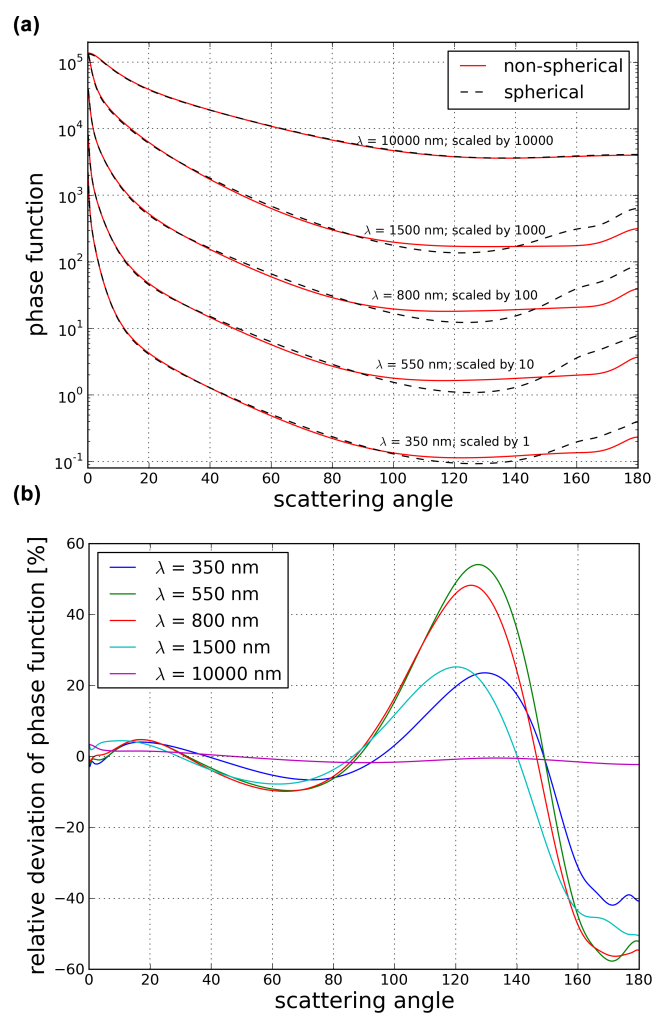

Figure 2. (a) Phase functions of desert aerosol for different wavelengths, assuming spherical and spheroidal mineral particles with a size- dependent aspect ratio distribution after Kandler C. For details see text. The scale of the phase functions for the different wavelengths is shifted by a factor 10 in each case. (b) Relative deviations $(\%)$ of phase functions assuming spheroidal mineral particles from phase functions of spherical particles, for desert aerosol and the conditions shown in (a).

sphere is less than that of smaller particles, in a dust storm not only the total amount of mineral particles in the air is high, but also the relative amount of large particles. During the transport, i.e. the time after the dust generation, the particle amount will be reduced due to sedimentation, but this effect can be stronger for larger particles. Finally, for background conditions, the total amount of mineral particles is low, and has the lowest amount of large particles (d'Almeida, 1987; Longtin et al., 1988; Tanré et al., 1988). The relative increasing amount of large particles with increasing turbidity that we assume to test the effect of non-sphericity with respect to particle size distribution is shown in Eqs. (2)-(4) (d'Almeida, 1987; Koepke et al., 1997). Given are correlations between the total number of mineral dust particles and the belonging numbers for the three mineral components.

$$
\begin{aligned}
& \ln N_{\text {MINM }}=0.104+0.963 \ln N_{\text {mineral }} \\
& \ln N_{\text {MIAM }}=-3.94+1.29 \ln N_{\text {mineral }} \\
& \ln N_{\text {MICM }}=-13.7+2.06 \ln N_{\text {mineral }}
\end{aligned}
$$




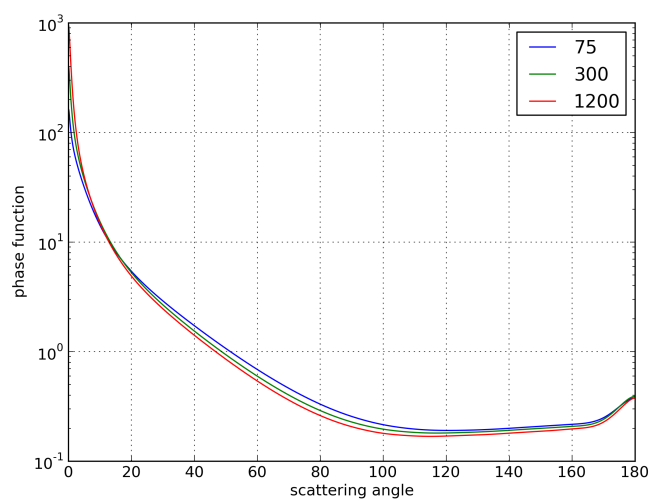

Figure 3. Phase functions of desert aerosol at $0.8 \mu \mathrm{m}$, with a mixture of the non-spherical mineral components MINM, MIAM and MICM after the Eqs. (2)-(4), using the total number of mineral particle $N_{\text {mineral }}$ given in the figure. In each case 2000 WASO particles assuming $0 \% \mathrm{RH}$ are included.

In Fig. 3, for desert aerosol with different turbidity, implemented with different total particle numbers, resulting in a different number of particles of the three mineral components, the phase functions for non-spherical desert particles are shown. $N_{\text {mineral }}$ gives the total number of mineral particles. $N_{\text {mineral }}=75$ stands for "background desert" conditions, $N_{\text {mineral }}=300$ for average "desert" and $N_{\text {mineral }}=1200$ for "dust storm". It can be seen that the general effect of the non-spherical particle shape is always given, but does not differ considerably for the different size distributions, as a result of different total particle numbers. The effect of varying size distribution is more pronounced in the forward peak and the sideward scattering.

As mentioned, the WASO particles are spheres, with the consequence that the variation of their amount changes the phase function of the mixture. This is shown in Fig. 4 for "desert" with different amounts of WASO on the one hand, and for an average amount of 2000 WASO particles, but in combination with mineral particles for "background" and for "dust storm" conditions on the other hand.

Figure 4 shows that the effects due to the particle shape increase from background over desert to dust storm if the number of WASO is fixed, simply due to the increasing amount of non-spherical mineral particles. On the contrary, the effect due to non-spherical shape is reduced, to be seen for the type "desert", if the amount of spherical WASO particles is increased. But it should be mentioned that the effect due to doubling or omitting WASO for the relative deviations of the phase function is less than the effect due to the variation of the amount of the mineral particles.

For the determination of the height dependent aerosol extinction coefficients, often backscatter lidar systems or ceilometers are used, because they are cheaper than higher sophisticated lidar instruments (Mona et al., 2012; Wiegner et al., 2014). However, for these instruments the measured

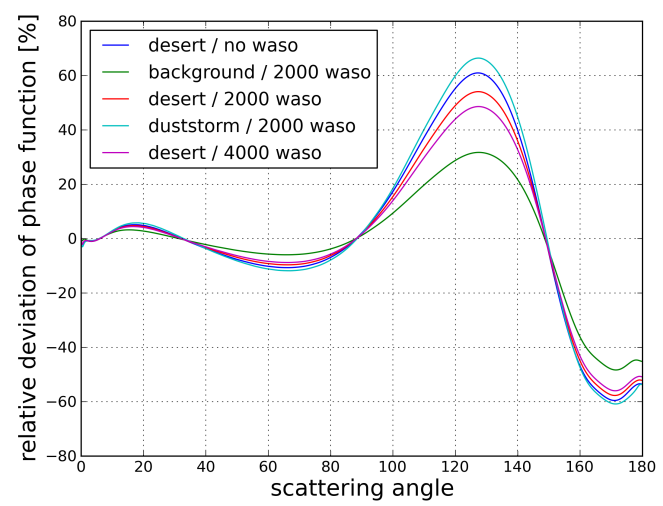

Figure 4. Relative deviations (\%) of phase functions at $0.55 \mu \mathrm{m}$, assuming spheroidal mineral particles, from phase functions of spherical particles, for different combinations of the components WASO, MINM, MIAM and MICM (for details see text).

signal is a result of both the extinction coefficient and the phase function at $180^{\circ}$. Thus, to get the interesting height dependent extinction coefficient, it is necessary to use a quantity "lidar ratio", which depends on the phase function and thus on the particle shape.

Figure 5 shows the lidar ratio for the aerosol type "desert", both under the assumption of non-spherical and spherical mineral particles. The values are given for a wavelength range up to $40 \mu \mathrm{m}$, although no lidar instruments are available for wavelength larger $\approx 2 \mu \mathrm{m}$. Moreover, for the large wavelengths, the particles behave more and more like spheres, as already seen in Fig. 2b. For the interesting wavelength range around and below $1 \mu \mathrm{m}$, however, the consideration of non-sphericity is essential. With respect to independently measured lidar ratios, the agreement with modeled values is much better under the assumption of spheroids than of spheres (Gobbi et al., 2002). The lidar ratios to be seen in Fig. 5 are in good agreement with measured values from SAMUM (Groß et al., 2011). This is also generally valid for all lidar-wavelengths that have been used during SAMUM, but here the agreement between measured and modeled lidar ratios was reduced for the wavelength $355 \mathrm{~nm}$, probably due to wrong assumptions with respect to the refractive index (Wiegner et al., 2009).

Optical quantities that are independent of the scattering angle or given as ratio between wavelengths are expected to be less sensitive with respect to the particle shape. To investigate this aspect, in Fig. 6 relative differences between spherical and non-spherical desert particles are presented for the spectral scattering-, absorption- and extinction-coefficients and for the asymmetry parameter. For all these quantities the deviations are less than $6 \%$ and even less than $4 \%$ in the part of the solar spectrum that is most relevant for climate effects. The same low dependency on the particle shape also holds for the single scattering albedo and the Ångström coefficient, not shown in a figure. 


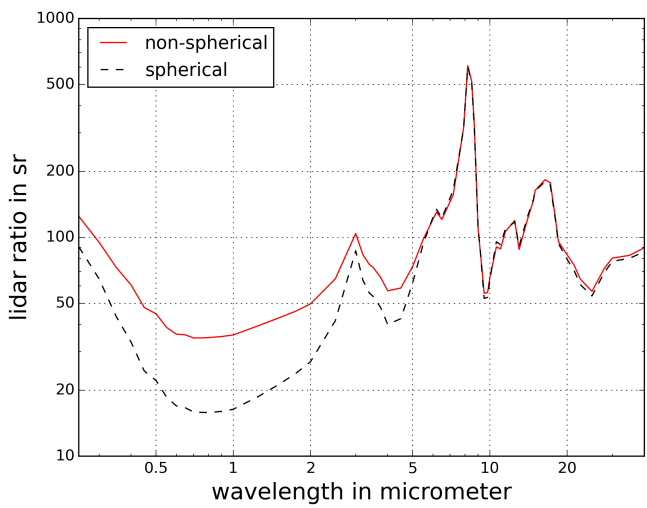

Figure 5. Modeled values of the lidar ratio for "desert" aerosol under the assumption of spherical and non-spherical particles.

Table 3. Reduction factors for particle volume and mass for the nonspherical mineral components, compared to the old components.

\begin{tabular}{ll}
\hline $\mathrm{MINM} \rightarrow$ MINN & 0.9754 \\
\hline $\mathrm{MIAM} \rightarrow$ MIAN & 0.9273 \\
\hline $\mathrm{MICM} \rightarrow$ MICN & 0.9273 \\
\hline
\end{tabular}

\section{New version: OPAC (4.0)}

The main improvement of the new version of OPAC is the consideration of the non-sphericity of mineral particles. In OPAC for all optical quantities the large wavelength range between 0.25 and $40 \mu \mathrm{m}$ is respected, with the consequence that the improved particle shape of mineral particles works both in the solar and in the infrared spectral region. Additionally, new in OPAC (4.0) is the possibility to model the particle mass for different cut-off radii, e.g. as used for $\mathrm{PM}_{10}$. On the other hand, the component "mineral-transported", MITR, is no longer considered. This component had been used to describe desert aerosol under very remote conditions, as part of aerosol in polar regions. However, the amount of mineral dust particles should be reduced continuously on its way from the source, depending on their life time. This is possible with the remaining mineral components (e.g. using Eqs. 2-4), instead of switching to MITR. Thus, the aerosol type "Antarctic" in OPAC has been modified.

As discussed in the paper, the shape of the mineral particles has been improved. To avoid mistakes, the new mineral components are named in the new OPAC version with an $N$ at the end, standing for non-spherical. The change from spheres to spheroids was made on the basis of cross section equivalence, resulting in a small reduction of the particle volume and thus the particle mass, resulting in the reduction factors shown in Table 3.

All the other microphysical aerosol properties are unchanged against the previous version of OPAC. Also the new version of OPAC gives the possibility to combine different

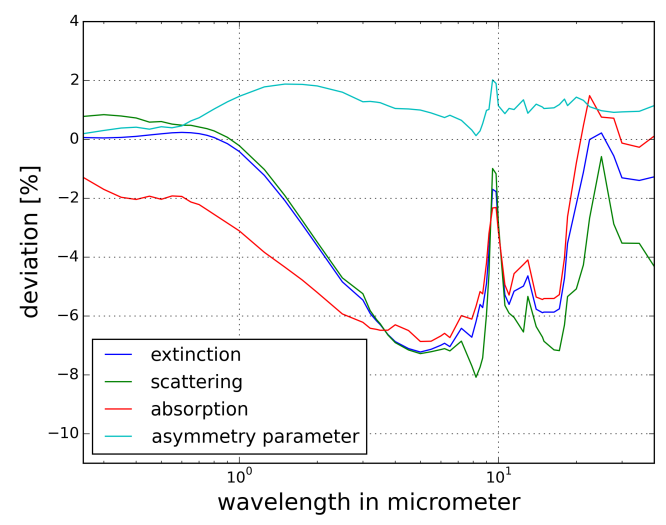

Figure 6. Deviation (\%), between spherical and non-spherical "desert" aerosol for different optical quantities.

aerosol components, in each case with individually decided particle number density for each component.

Results of OPAC (4.0) are a large number of optical properties (like phase function, scattering- absorption- and extinction coefficient, asymmetry parameter, single scattering albedo, Ångström coefficient, lidar ratio and visibility) and particle mass per volume. All properties can be modeled for different relative humidity and the optical properties are available as spectral values for the wide wavelength range of 0.25 to $40 \mu \mathrm{m}$ and spectrally weighted for the solar and terrestrial range. For non-commercial use OPAC (4.0) is freely available at www.rascin.net.

\section{Conclusion}

Aerosol particles are one of the main gaps in the present knowledge of radiative forcing (Myhre et al., 2013), and mineral particles are especially essential due to their large amount and temporal and spatial variability. Since mineral particles in general are not spheres, Mie theory may lead to wrong values, both, if their optical properties are modeled based on size distribution and refractive index, and if remotesensing data are used to get aerosol properties. Thus, the optical properties of mineral particles in the new version of OPAC are derived using TMM for spheroids. As described in this paper the non-sphericity is given by typical size dependent aspect ratio distributions of spheroids, which have been derived from measurements at observation campaigns. The predefined components in OPAC, now also for non-spherical mineral particles, are a big convenience, because users do not need to decide for individual single particle properties, as available from various studies and databases (Nousiainen, 2009; Meng et al., 2010).

The differences between spherical and non-spherical mineral particles are shown for a wide range of optical properties of desert aerosols. They are small, nearly negligible in the case of angular-independent optical quantities, like 
extinction-, scattering- and absorption-coefficients, asymmetry factor, single scattering albedo, and Ångström coefficient. However, the differences between spherical and nonspherical particles are large, up to $60 \%$, in the sideward and backward scattering regions of the phase functions in the solar spectral range. As a consequence, the deviations are also large in the lidar ratio, a parameter required to get height dependent extinction values from often used backscatter lidar measurements. The effect of the particle shape decreases with wavelength, since at wavelengths that are rather large with respect to the particle size, the particle shape is of less relevance.

It should be born in mind that the size distribution and the complex refractive index of the aerosol particles are very important for their optical properties. For the radiative properties in the thermal infrared the uncertainty in the refractive index will outperform the shape effect, which moreover depends on the absorption of the particles (Legrand et al., 2014). However, in this article only the aspect of the shape of mineral particle is discussed, and in the new version of OPAC the shape of the mineral particles has been improved, but the assumed size distributions and spectral refractive indices have not been changed. This will be done in the future, where it is planned also to add a stronger absorbing mineral component that allows for a larger variability of mixtures to describe desert aerosol.

Since the solar spectral range is often used for remotesensing of aerosol particles and relevant for aerosol radiative forcing, the consideration of the phase functions of nonspherical mineral particles is a real improvement of OPAC, now available as version 4.0.

Acknowledgements. This publication was partly funded by LMU Munich's Institutional Strategy LMUexcellent within the framework of the German Excellence Initiative.

Edited by: P. Formenti

\section{References}

d'Almeida, G. A.: On the variability of desert aerosol radiative characteristics, J. Geophys. Res., 92, 3017-3026, 1987.

d'Almeida, G. A., Koepke, P., and Shettle, E. P.: Atmospheric aerosols, A. Deepak Publ. Hampton, Virginia, USA, 561 pp., 1991.

Cheng, R. J.: Physical properties of atmospheric particulates, in: Light scattering by irregularly shaped particles, edited by: Schuerman, D. W., Plenum Press, New York, USA, 69-78, 1980.

Deepak, A. and Gerber, H. E.: Report of the experts meeting on aerosols and their climatic effects, WCP-55, World Meteorolog. Org., Geneva, Switzerland, 107 pp., 1983.

Dubovik, O., Sinyuk, A., Lapyonok, T., Holben, B. N., Mishchenko, M. I., Yang, P., Eck, T. F., Volten, H., Munoz, O., Veihelmann, B., van der Zande, W. J., Leon, J. F., Sorokin, M., and Slutsker,
I.: Application of spheroid models to account for aerosol particle non-sphericity in remote sensing of desert dust, J. Geophys. Res.Atmos., 111, D11208, doi:10.1029/2005JD006619, 2006.

Falkovich, A. H., Gomez, E., Lewin, Z., Formenti, P., and Rudich, Y.: Analysis of individual dust particles, J. Geophys. Res.Atmos., 106, 18029-18036, 2001.

Gasteiger, J., Groß, S., Freudenthaler, V., and Wiegner, M.: Volcanic ash from Iceland over Munich: mass concentration retrieved from ground-based remote sensing measurements, Atmos. Chem. Phys., 11, 2209-2223, doi:10.5194/acp-11-22092011, 2011.

Gasteiger, J. K.: Retrieval of microphysical properties of desert dust and volcanic ash aeosols from ground-based remote sensing, Diss. Univ. Muenchen, 124 pp., 2011.

Gobbi, G. P., Barnaba, F., Blumthaler, M., Labow, G., and Herman, J. R.: Observed effects of particles non-sphericity on the retrieval of marine and desert dust aerosol optical depth by lidar, Atmos. Res., 61, 1-14, 2002.

Groß, S., Tesche, M., Freudenthaler, V., Toledano, C., Wiegner, M., Ansmann, A., Althausen, D., and Seefeldner, M.: Characterization of Saharan dust, marine aerosols and mixtures of biomassburning aerosols and dust by means of multi-wavelength depolarization and Raman lidar measurements during SAMUM 2, Tellus B, 63, 706-724, 2011.

Haywood, J. M. and Boucher, O.: Estimates of direct and indirect radiative forcing due to tropospheric aerosol: A review, Rev. Geophys., 38, 513-543, 2000.

Haywood, J. M., Francis, P. N., Glew, M. D., and Taylor, J. P.: Optical properties and direct radiative effect of Saharan dust: A case study of two Saharan dust outbreaks using aircraft data, J. Geophys. Res.-Atmos., 106, 18417-18430., 2001

Heintzenberg, J.: The SAMUM-1 experiment over Southern Morocco: overview and introduction, Tellus B, 61, 2-11, 2009.

Hess, M., Koepke, P., and Schult, I.: Optical properties of aerosols and clouds: The software package OPAC, B. Am. Meteorol. Soc., 79, 831-844, 1998.

Horvath, H., Kasahara, M., Tohno, S., and Kocifaj, M.: Angular scattering of the Gobi desert aerosol and its influence on radiative forcing, J. Aerosol Sci., 37, 1287-1302, 2006.

Kalashnikova, O. V. and Sokolik, I. N.: Importance of shapes and compositions of wind-blown dust particles for remote sensing at solar wavelengths, Geophys. Res. Lett., 29, 38.1-38.4, 2002.

Kahnert, F. M.: Numerical methods in electromagnetic scattering theory, J. Quant. Spectrosc. Ra., 79, 775-824, 2003.

Kahnert, M., Nousiainen, T., and Veihelmann, B.: Spherical and spheroidal model particles as an error source in aerosol climate forcing and radiance computations: A case study for feldspar aerosols, J. Geophys. Res.-Atmos., 110, D18S13, doi:10.1029/2004JD005558, 2005.

Kandler, K., Schütz, L., Deutscher, C., Ebert, M., Hofmann, H., Jäckel, S., Jaenicke, R., Knippertz, P., Lieke, K., Massling, A., Petzold, A., Schladitz, A., Weinzierl, B., Wiedensohler, A., Zorn, S., and Weinbruch, S.: Size distributions, mass concentrations, chemical and mineralogical composition, and derived optical parameters of the boundary layer aerosol at Tinfou, Morocco, during SAMUM 2006, Tellus B, 61, 32-50, 2009.

Kandler, K., Lieke, K., Benker, N., Emmel, C., Küpper, M., MüllerEbert, D., Scheuvens, D., Schladitz, A., Schütz, L., and Weinbruch, S.: Electron microscopy of particles collected at Praia, 
Cap Verde, during the Saharan mineral dust experiment: particle chemistry, shape, mixing state and complex refractive indices, Tellus B, 63, 457-496, 2011.

Kaufmann, Y. J.: Measurements of the optical thickness and the path radiance - Implications on aerosol remote sensing and atmospheric corrections, J. Geophys. Res., 98, 2677-2692, 1993.

Kinne, S., Schulz, M., Textor, C., Guibert, S., Balkanski, Y., Bauer, S. E., Berntsen, T., Berglen, T. F., Boucher, O., Chin, M., Collins, W., Dentener, F., Diehl, T., Easter, R., Feichter, J., Fillmore, D., Ghan, S., Ginoux, P., Gong, S., Grini, A., Hendricks, J., Herzog, M., Horowitz, L., Isaksen, I., Iversen, T., Kirkevåg, A., Kloster, S., Koch, D., Kristjansson, J. E., Krol, M., Lauer, A., Lamarque, J. F., Lesins, G., Liu, X., Lohmann, U., Montanaro, V., Myhre, G., Penner, J., Pitari, G., Reddy, S., Seland, O., Stier, P., Takemura, T., and Tie, X.: An AeroCom initial assessment - optical properties in aerosol component modules of global models, Atmos. Chem. Phys., 6, 1815-1834, doi:10.5194/acp-6-1815-2006, 2006.

Koepke, P. and Hess, M.: Scattering functions of tropospheric aerosols: the effects of non-spherical particles, Appl. Optics, 27, 2422-2430, 1988.

Koepke, P. and Quenzel, H.: Turbidity of the atmosphere determined from satellite, J. Geophys. Res., 84, 7847-7856, 1979.

Koepke, P., Hess, M., Schult, I., and Shettle, E. P.: Global Aerosol Data Set, Report No. 243, MPI Hamburg, Germany, 44 pp., 1997.

Lacis, A. A. and Mishchenko, M. I.: Climate forcing, climate sensitivity, and climate response: a radiative modeling perspective on atmospheric aerosols, in: Aerosol forcing of climate, edited by: Charlson, R. J. and Heintzenberg, J., John Wiley \& Sons, 11-42, 1995.

Legrand, M., Dubovik, O., Lapyonok, T., and Derimian, Y.: Accounting for particle non-sphericity in modeling mineral dust radiative properties in the thermal infrared, J. Quant. Spectrosc. Ra., 149, 219-240, 2014.

Longtin, D. R., Shettle, E. P., Hummel, J. R., and Pryce, J. D.: A desert aerosol model for radiative transfer studies, in: Aerosols and climate, edited by: Hobbs, P. V. and McCormick, M. P., A. Deepak Publ., Hampton Virginia, USA, 261-269, 1988.

McCormick, R. A. and Ludwig, J. H.: Climate modification by atmospheric aerosols, Science, 156, 1358-1359, 1967.

Meng, Z., Yang, P., Kattawar, G. W., Bi, L., Liou, K. N., and Laszlo, I.: Single-scattering properties of tri-axial ellipsoidal mineral dust aerosols: A database for application to radiative transfer calculations, J. Aerosol Sci., 41, 501-512, 2010.

Mie, G.: Beiträge zur Optik trüber Medien, speziell kolloidaler Metallösungen, Ann. Physik, 25, 377-445, 1908.

Mishchenko, M. I. and Travis, L. D.: Capabilities and limitations of a current Fortran implementation of the T-Matrix method for randomly oriented, rotationally symmetric scatterers, J. Quant. Spectrosc. Ra., 60, 309-324, 1998.

Mishchenko, M. I., Travis, L. D., Kahn, R. A., and West, R. A.: Modeling phase functions for dust-like tropospheric aerosols using a shape mixture of randomly oriented polydisperse spheroids, J. Geophys. Res., 102, 13543-13553, 1997.

Mishchenko, M. I., Hovenier, J. W., and Travis, L. D. (Eds): Light scattering by nonspherical particles: Theory, measurements, and applications, Academic Press, San Diego, USA, 2000.

Mona, L., Liu, Z., Müller, D., Omar, A., Papayannis, A., Pappalardo, G., Sugimoto, N., and Vaughan, M.: Lidar measure- ments for desert dust characterization: An Overview, Adv. Meteorol., 2012, ID356265, 36 pp., 2012.

Müller, D., Weinzierl, B., Petzold, A., Kandler, K., Ansmann, A., Müller, T., Tesche, M., Freudenthaler, V., Esselborn, M., Heese, B., Althausen, D., Schaditz, A., Otto, S., and Knippertzt, P.: Mineral dust observed with AERONET Sun photometer, Raman lidar, and in situ instruments during SAMUM 2006: Shapeindependent particle properties, J. Geophys. Res.-Atmos., 115, D07202, doi:10.1029/2009JD012520, 2010.

Myhre, G., Shindell, D., Bréon, F.-M., Collins, W., Fuglestvedt, J., Huang, J., Koch, D., Lamarque, J.-F., Lee, D., Mendoza, B., Nakajima, T., Robock, A., Stephens, G., Takemura, T., and Zhanh, H.: Anthropogenic and natural radiative forcing, in: Climate Change 2013, edited by: Stocker, T. F., Qin, D., Plattner, G.-K., Tignor, M., Allen, S. K., Boschung, J., Nauels, A., Xia, Y., Bex, V., and Midgley, P. M., Cambridge Univ. Press, Cambrige, UK, and New York, USA, 2013.

Nousiainen, T.: Optical modeling of mineral dust particles: A review, J. Quant. Spectrosc. Ra., 110, 1261-1279, 2009.

Nousiainen, T. and Vermeulen, K.: Comparison of measured singlescattering matrix of feldspar with T-matrix simulations using spheroids, J. Quant. Spectrosc. Ra., 79, 1031-1042, 2003.

Sakai, T., Orikasa, N., Nagai, T., Murakami, M., Tajiri, T., Saito, A., Yamashita, K., and Hashimoto, A.: Balloon-borne and Raman lidar observations of Asian dust and cirrus cloud properties over Tsukuba, Japan, J. Geophys. Res.-Atmos., 119, 3295-3308, 2014.

Shettle, E. P. and Fenn, R. W.: Models for the aerosols of the lower atmosphere and the effects of humidity variations on their optical properties, Report AFGL-TR-79-0214, AFGL, Hanscom AFB, Mass, USA, 94 pp., 1979.

Sokolik, I. N., Winker, D. M., Bergametti, G., Gilette, D. A., Carmichel, G., Kaufmann, Y. J., Gomes, L., Schmetz, L., and Penner, J. E.: Introduction to special section: outstanding problems in quantifying the radiative impacts of mineral dust, J. Geophys. Res.-Atmos., 106, 18015-18027, 2001.

Tanré, D., Devaux, C., Herman, M., and Santer, R.: Radiative properties of desert aerosols by optical ground-based measurements at solar wavelengths, J. Geophys. Res.-Atmos., 93, 1422314231, 1988.

Waterman, P.: Symmetry, unitarity, and geometry in electromagnetic scattering, Phys. Rev., 3, 825-839, 1971.

Weinzierl, B., Petzold, A., Esselborn, M., Wirth, M., Rasp, K., Kandler, K., Schütz, L., Koepke, P., and Fiebig, M.: Airborne measurements of dust layer properties, particle size distribution and mixing state of Saharan dust during SAMUM 2006, Tellus B, 61, 96-117, 2009.

Wiegner, M., Gasteiger, J., Kandler, K., Weinzierl, B., Rasp, K., Esselborn, M., Freudenthaler, V., Heese, B., Toledano, C., Tesche, M., and Althausen, D.: Numerical simulations of optical properties of Saharan dust aerosols with emphasis on lidar applications, Tellus B, 61, 180-194, 2009.

Wiegner, M., Madonna, F., Binietoglou, I., Forkel, R., Gasteiger, J., Geiß, A., Pappalardo, G., Schäfer, K., and Thomas, W.: What is the benefit of ceilometers for aerosol remote sensing? An answer from EARLINET, Atmos. Meas. Tech., 7, 1979-1997, doi:10.5194/amt-7-1979-2014, 2014.

Yang, P., Feng, Q., Hong, G., Kattawar, G. W., Wiscombe, W. J., Mishchenko, M. I., Dubovik, O., Laszlo, I., and Sokolik, I. N.: 
Modeling of the scattering and radiative properties of nonspherical dust-like aerosols, J. Aerosol Sci., 38, 995-1014, 2007.

Yi, B., Hsu, C. N., Yang, P., and Tsay, S.-C.: Radiative transfer simulation of dust-like aerosols: Uncertainties from particle shape and refractive index, J. Aerosol Sci., 42, 631-644, 2011.
Zerull, R. H., Giese, R. H., Schwill, S., and Weiss, K.: Scattering by particles of nonspherical shape, in: Light scattering by irregularly shaped particles, edited by: Schuerman, D. W., Plenum Press, New York, USA, 273-282, 1980. 